\title{
Assessment of ground pressure through soil-structure interaction
}

Jeff Hsi PhD, MSc, BSc

Technical Principal, EIC Activities (a Member of the Cimic Group), Sydney, Australia (Orcid:0000-0003-1837-4556)

Chenhui Lee PhD, BEng (Civil Env Eng) (Hons)

Senior Associate, Geotechnical \& Tunnels, Smec, Sydney, Australia

(corresponding author: dr.chenhui.lee@smec.com)

(Orcid:0000-0002-7173-8614)
Thomas Miller PhD, BEng (Civil) (Hons)

Senior Engineer, Geotechnical \& Tunnels, Smec, Sydney, Australia

(Orcid:0000-0001-9554-3638)

The Sydney Metro Northwest involves construction of a fully automated metro rail network in New South Wales, Australia. The underground stations are delivered under two contracts: the Tunnels and Station Civils contract, responsible for the excavation and temporary support, and the Operations, Trains and Systems contract, responsible for the station structures. At the Castle Hill station, the excavation intersects a regional Dural Dome fault, resulting in a rock wedge measuring approximately $20 \mathrm{~m}$ high by $80 \mathrm{~m}$ long being exposed during excavation. Due to the limited design life of the temporary support, the ground pressure will ultimately be transferred to the station walls. Capturing this, as well as the beneficial effects of the stress relaxation due to the initial excavation, is crucial in achieving an optimised design. This paper presents the integrated ground-structure interaction approach adopted for the permanent walls' design, which resulted in optimised design ground pressures and station wall thicknesses.

\author{
Notation \\ $c^{\prime} \quad$ effective cohesion \\ $E^{\prime} \quad$ effective Young's modulus \\ $\gamma_{\mathrm{b}} \quad$ bulb unit weight \\ $v \quad$ drained Poisson's ratio \\ $\sigma_{\mathrm{v}} \quad$ overburden pressure \\ $\phi^{\prime} \quad$ effective angle of friction
}

\section{Introduction}

Sydney Metro Northwest is part of Australia's largest infrastructure project and will connect the north-west growth areas of Sydney to Chatswood through a fully automated metro rail system with eight new stations and $36 \mathrm{~km}$ of rail track. The $\mathrm{A} \$ 8.3$ billion $(\mathrm{A} \$ 1=\mathrm{US} \$ 0.75)$ project is being delivered under three contracts. The $15 \mathrm{~km}$ twin tunnels, station box excavations and temporary ground support are part of the Tunnels and Station Civils (TSC) contract. The permanent station box, commuter car park and metro train infrastructure and rail system are part of the Operations, Trains and Systems (OTS) contract. The $4 \mathrm{~km}$ elevated skytrain viaduct between Bella Vista and Rouse Hill are part of the Surface and Viaduct Civil contract.

As part of this project, five underground stations will be constructed. The A $\$ 1 \cdot 15$ billion TSC contract involves excavation of the station boxes and providing temporary ground support with 10 years of design life for these excavations. The temporary ground support typically comprises prestressed anchors and bored pile walls for the weathered rock and spot rock bolts for fresh rock. Following the completion of excavation and tunnelling works, part of the A $\$ 3.7$ billion OTS contract involves constructing the permanent ground support with 100 years' design life for the station boxes. The permanent ground support system is constructed directly in front of the temporary support and comprises reinforced-concrete walls propped by load-transfer structures and station floor slab.

Due to the limited design life of the temporary support, the ground pressure acting on the temporary support will eventually be transferred onto the station structures. One of the key challenges in the design of the permanent ground support system was to develop a holistic approach enabling the effects of intricate ground stress relaxation history and ground-structure interaction to be considered. This is a crucial step towards optimisation of the station wall thicknesses. Moreover, the weight of the wall will dictate the suitability of the segmental precast reinforced-concrete wall construction technique, which is desirable from the constructability standpoint due to faster construction cycles, better quality control and so on. As such, assessment of ground pressures post-degradation of the temporary support plays a pivotal role in optimising the station wall thicknesses. This paper presents the integrated ground-structure interaction approach adopted for the design of the permanent walls.

\section{Castle Hill station}

Castle Hill station is one of the deepest underground stations, located approximately $26 \mathrm{~km}$ north-west of the Sydney central business district. The station is located between the Old Northern Road and Old Castle Hill Road (Figure 1(a)), opposite the Castle Towers Shopping Centre. The station is approximately $196 \mathrm{~m}$ long and $22 \mathrm{~m}$ wide and has an excavation depth of approximately $25 \mathrm{~m}$ within the Permo-Triassic aged sedimentary rocks. The station structure is composed of reinforced-concrete walls propped by internal slabs (Figure 1(b)). The station is accessible through the concourse level through escalators and lifts and has been designed to allow natural light to flow through several openings into the station. This requirement increases the floor-to-floor heights and reduces the internal propping of the station box walls. 


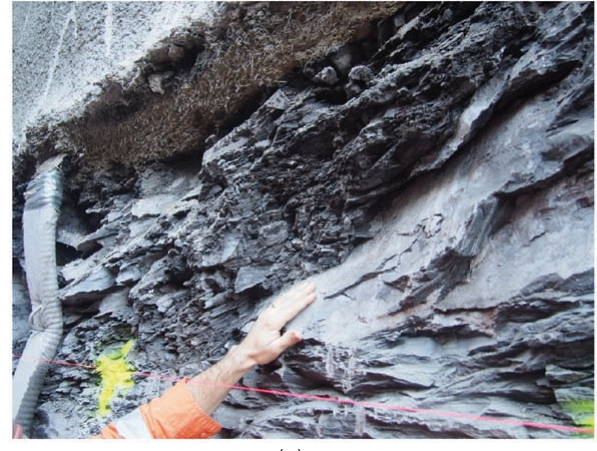

(a)

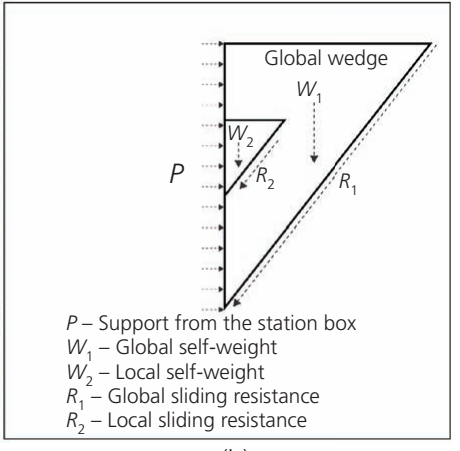

(b)

Figure 3. (a) Close-up of the exposed DD fault near the base of the excavation; (b) global and local wedge loads

relaxation. In addition, the impact of earthquakes and groundwater must also be considered. The way in which these were assessed is summarised in the following.

- The failure of rock wedges is associated with distinctive blocks of rock formed by the intersection of discontinuities, which may be free to fall or slide from the excavation periphery. This mechanism is examined through kinematic stability analysis.

- The ground stress relaxation is associated with the stability and lateral pressure imposed by the retained ground mass to the adjoining retaining wall. The pressure is assessed through finite-element analysis (FEA).

- The additional load and deformation imposed on the station box walls during an earthquake are due to $(a)$ the instability of rock wedges and $(b)$ ground shaking and the associated deformation. These are assessed through kinematic stability analysis and pseudo-static FEA.

- Due to the drained structure design requirements and permanent subsoil drains, the groundwater pressure acting on the station box walls is minimal.
The estimated ground pressure acting behind the temporary support piles was determined as the envelope of the kinematic wedge pressure and residual lateral pressure after the excavation.

\section{Kinematic analysis}

Kinematic analysis was undertaken using the defect orientation data obtained from the geology and discontinuity mapping records. The critical defect information recorded comprises the (a) physical location of the defect on the excavated wall; (b) type (e.g. fault, joint); (c) orientation (i.e. dip, dip direction); $(d)$ roughness; (e) infill material and thickness; $(f)$ shape (e.g. undulation or planar); $(g$ ) spacing or frequency; and $(h)$ persistence, length and height. Figure 4 shows the example geology and discontinuity mapping records from the TSC excavation.

At Castle Hill station, the following kinematic failure mechanism has been considered (Figure 3(b))

- wedge loading associated with local stability due to joint, faults, bedding, fractured zones or other discontinuity types, which was assessed through kinematic analysis (Figure 5(a))

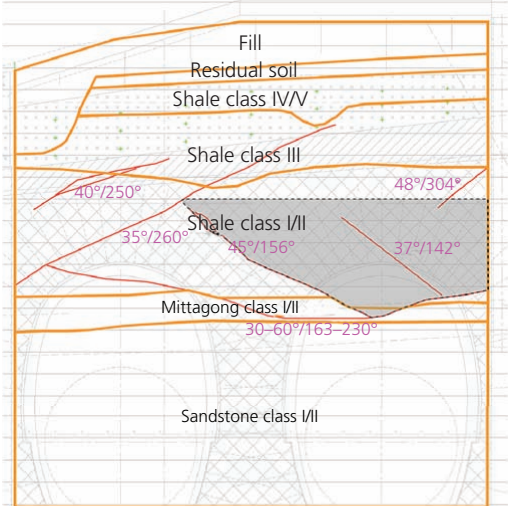

(a)

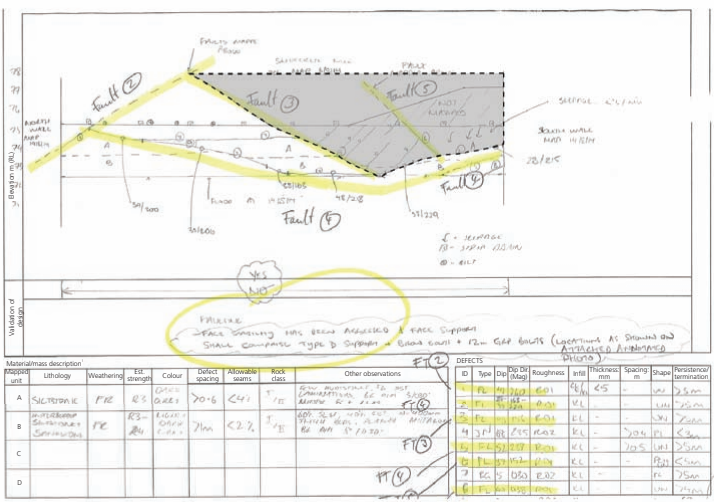

(b)

Figure 4. (a) Example of subsurface profile with rock wedge; (b) corresponding geology and discontinuity mapping sheet from the TSC excavation 


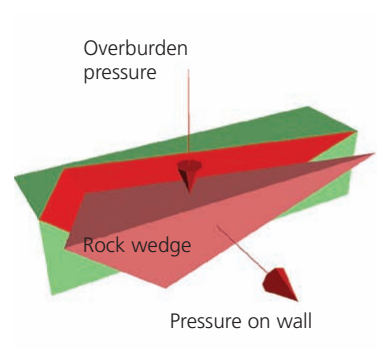

(a)

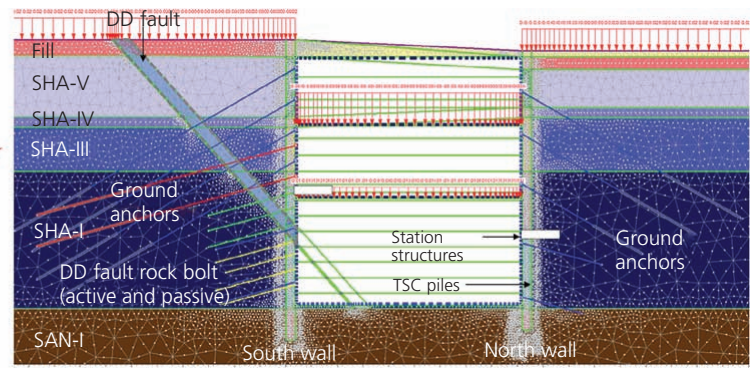

(b)

Figure 5. (a) Kinematic analysis of the rock wedge; (b) FE mesh. SHA, Ashfield Shale; SAN, Hawkesbury Sandstone

wedge loading associated with global stability due to the regional DD fault; the failure plane as mapped was modelled in FEA (Figure 5(b)).

Kinematic analysis using the stereographic projection software Rocscience Dips was used to determine the likely rock failure modes (i.e. planar, wedge, toppling etc.). The risk rating associated with different modes of failure was assessed. The assessment indicated that the risk rating associated with wedge sliding is high, whereas the risk rating associated with topping failure is low considering that this mode of failure is limited to a small single wedge caused by the intersection of two joints, rather than a series of joints that can trigger a large-scale instability. The pressure due to toppling and planar failures was assessed to be lower than that imposed by wedge failures.

The pressure imposed by wedge failure has been assessed using Rocscience Swedge as shown in Figure 5(a). The orientation of the intersecting discontinuities was analysed. The discontinuity shear strength was derived based on the shear box testing and available information such as the discontinuity roughness, infill material, weathering and lithology of the rock. Scaling of the rock wedges based on the height of exposed face was undertaken to match the mapping sheet. This is crucial because for a given set of discontinuities considered, the maximum possible wedge size can be much larger than that encountered in the field. The scaling ensures the predicted pressure is relevant.

\section{Finite-element analysis}

FEA of the ground stress was undertaken using Rocscience RS2, and the results for the city end of the station where the excavation intersected the DD fault are presented. The staged excavation followed by ground anchor/bolt installation was modelled in RS2. The estimated ground pressure acting behind the temporary support piles was determined as the envelope from the residual lateral pressure after the excavation and the kinematic wedge pressure. Because the plane strain FE model cannot explicitly consider the blocks formed by discontinuities, which may be free to fall or slide, the pressure associated with the kinematic instability needs to be considered explicitly as an applied pressure. As an individual rock wedge starts to detach from the ground, the rock pressure acting on the block would reduce to zero. Hence, the applied wedge loading was derived as the difference between the kinematic and the residual pressure. No additional pressure will be applied when the residual pressure is higher than the kinematic pressure.

\section{Geotechnical model and groundwater}

The finite-element (FE) model was calibrated by comparing the predicted ground movements with the field measurements. The ground properties, wedge loading and field stresses were slightly adjusted until the predicted ground movements were consistent with the field measurements. The geotechnical model adopted for the back-analysis is given in Table 2 . The soil is dry and modelled as drained. The rocks are classified into five strength categories according to the Pells et al. (1998) method (i.e. class V - low

Table 2. Subsurface profile and geotechnical parameters

\begin{tabular}{|c|c|c|c|c|c|c|c|}
\hline \multirow{2}{*}{ Layer } & \multicolumn{2}{|c|}{ Wall RL (top) } & \multirow{2}{*}{$\gamma_{\mathrm{b}}: \mathrm{kN} / \mathrm{m}^{3}$} & \multirow{2}{*}{$c^{\prime}: \mathrm{kPa}$} & \multirow{2}{*}{$\phi^{\prime}: \circ$} & \multirow{2}{*}{$E^{\prime}: \mathrm{MPa}$} & \multirow{2}{*}{$v$} \\
\hline & South & North & & & & & \\
\hline Residual soil & $142 \cdot 8$ & $141 \cdot 2$ & $20 \cdot 0$ & 8 & 28 & 20 & $0 \cdot 3$ \\
\hline SHA-V & $141 \cdot 2$ & 139.9 & $21 \cdot 0$ & 10 & 28 & 50 & $0 \cdot 3$ \\
\hline SHA-IV & $135 \cdot 3$ & $136 \cdot 2$ & $22 \cdot 0$ & 20 & 30 & 150 & 0.3 \\
\hline SHA-III & $134 \cdot 3$ & $135 \cdot 2$ & $23 \cdot 0$ & 100 & 30 & 300 & 0.3 \\
\hline SHA-II & 131.6 & $130 \cdot 6$ & $24 \cdot 0$ & 150 & 30 & 700 & 0.2 \\
\hline SHA-I & $130 \cdot 0$ & $130 \cdot 0$ & $24 \cdot 0$ & 350 & 30 & 1500 & 0.2 \\
\hline SAN-I & $116 \cdot 7$ & $116 \cdot 7$ & $24 \cdot 0$ & 500 & 37 & 2000 & 0.2 \\
\hline
\end{tabular}

RL, reduced level; SHA, Ashfield Shale; SAN, Hawkesbury Sandstone 
strength, class I - high strength), which takes into account the defect spacing, allowable seams and unconfined compressive strength. The equivalent Mohr-Coulomb criteria were derived from Hoek-Brown failure criteria using the rock mass strength software RocLab. The DD fault plane was modelled as a $1 \mathrm{~m}$ thick class IV shale (SHA-IV) due to the increase in the defects and was underlain by about $100 \mathrm{~mm}$ thick clay infill with shear strength parameters $\phi^{\prime}=20^{\circ}$ and $c^{\prime}=10 \mathrm{kPa}$.

The initial groundwater table was assumed at reduced level (RL) $135 \mathrm{~m}$ Australian Height Datum (AHD) based on the measured groundwater level from the grout-in-place vibrating wire piezometers. Temporary horizontal drains and strip drains were installed during excavation, and the groundwater monitoring shows that the water level at the excavated face has been drawn down to the base of excavation. This drawdown has been modelled in the FEA by using steady-state seepage analysis. To prevent the buildup of water pressure in the long term, the permanent drainage system is composed of subhorizontal drains, strip drains, an underfloor Cavidrain layer and a drainage flushing system.

\section{In situ locked-in stresses}

The dock at depth is subjected to stresses both due to the selfweight of the overlying strata and from locked-in stresses. When the station box is excavated, the stress field is locally disturbed and a new set of stresses is induced in the rock surrounding the excavation. As such, knowledge of the magnitudes and directions of these stresses before the excavation is an essential component of the ground support design.

Within the Sydney Basin, the locked-in stress in fresh rock can be many times higher than the overburden stress. In situ testing using

Table 3. In situ horizontal field stresses in station box orientation

\begin{tabular}{|ccc|} 
Layer & $\begin{array}{c}\text { Perpendicular to } \\
\text { wall: MPa }\end{array}$ & $\begin{array}{c}\text { Parallel to } \\
\text { wall: } \mathbf{M P a}\end{array}$ \\
\hline $\begin{array}{c}\text { Residual soil } \\
\text { SHA-V/SHA- }\end{array}$ & $0.7 \sigma_{\mathrm{v}}$ & $0.7 \sigma_{\mathrm{v}}$ \\
IV/SHA-III & $1 \sigma_{v}$ & $1 \sigma_{v}$ \\
SHA-II/SHA-I & $1.75 \sigma_{v}+0.39$ & $1.65 \sigma_{v}+0.37$ \\
SAN-II/SAN-I & $1.75 \sigma_{v}+1.97$ & $1.65 \sigma_{\mathrm{v}}+1.85$ \\
\hline
\end{tabular}

$\sigma_{\mathrm{v}}$, overburden stress overcoring and hydro-fracture methods was undertaken to measure the in situ major and minor principal locked-in stresses. The rock stress perpendicular to the station wall was then obtained from the major and minor principal lateral rock stresses by using Mohr's circle analysis. The resolved stresses were then calibrated with the measured ground movement. The calibrated stresses through back-analysis are summarised in Table 3 .

\section{Finite-element mesh}

The FE mesh with the temporary and permanent ground support are shown in Figure 5(b) and the structural properties are shown in Table 4. The excavation is temporarily supported by active ground anchors and $900 \mathrm{~mm}$ dia. piles installed at a centre-tocentre spacing of $2.5 \mathrm{~m}$. In the FEA, the ground anchors and rock bolts were modelled, respectively, using a tie-back bolt and a fully bonded bolt in RS2. The temporary piles were modelled as an elastic six-noded triangle element solid element with a very fine mesh and equivalent 'smeared' pile properties during excavation and reassigned to the in situ ground properties in the long term to simulate fully degraded piles. The analysis is not sensitive to the use of interface element; therefore, interface element has not been considered in the final FE model. The permanent station walls and floor slabs were modelled in front of the piles as a liner element.

\section{Results of the back-analysis of the station excavation}

The lateral movements of the excavated face measured by the optical survey targets are presented in Figure 6. The results show that the FE model was able to predict a similar magnitude of deformation compared to the field measurements. Thus, the model was calibrated and used for the prediction of permanent support ground pressure through ground-structure interaction analysis.

It is assessed that the station wall would not experience pressures from further fault movements, in view of the station being located on the top of hill and the rock formation in the Sydney Basin being relatively stable with no evidence of ongoing active tectonic movement.

\section{Integrated soil-structure interaction approach}

An integrated ground-structure interaction approach was adopted between the geotechnical and structural analyses. The aim was to obtain agreement between the geotechnical and structural

Table 4. Structural properties

\begin{tabular}{|c|c|c|c|c|c|c|c|c|}
\hline $\begin{array}{l}\text { Structural } \\
\text { type }\end{array}$ & Element type & $E^{\prime}: \mathrm{MPa}$ & $v$ & $\begin{array}{l}\text { Thickness: } \\
\text { m }\end{array}$ & $\begin{array}{l}\text { Bolt diameter: } \\
\qquad \mathrm{mm}\end{array}$ & $\begin{array}{l}\text { Bond shear stiffness: } \\
\qquad \mathrm{MN} /(\mathrm{m} \mathrm{m})\end{array}$ & $\begin{array}{l}\text { Bore diameter: } \\
\qquad \mathrm{mm}\end{array}$ & $\begin{array}{l}\text { Spacing: } \\
\mathrm{m}\end{array}$ \\
\hline TSC piles & Six-noded triangle & 10000 & $0 \cdot 3$ & N/A & $\mathrm{N} / \mathrm{A}$ & N/A & 900 & $2 \cdot 50$ \\
\hline $\begin{array}{l}\text { Degraded } \\
\text { TSC piles }\end{array}$ & element & $\begin{array}{l}\text { Grounc } \\
\text { properti }\end{array}$ & & N/A & $\mathrm{N} / \mathrm{A}$ & N/A & $\mathrm{N} / \mathrm{A}$ & $2 \cdot 50$ \\
\hline TSC anchors & Tie-back & 200000 & N/A & N/A & 34 & 808 & 100 & $2 \cdot 50$ \\
\hline TSC bolts & Fully bonded & 200000 & N/A & N/A & 24 & N/A & N/A & $1 \cdot 75$ \\
\hline Wall & Liner & 32000 & $0 \cdot 2$ & $0 \cdot 4$ & N/A & N/A & N/A & N/A \\
\hline Slab & Liner & 32000 & $0 \cdot 2$ & $0 \cdot 3$ & N/A & N/A & N/A & N/A \\
\hline
\end{tabular}

N/A, not applicable 


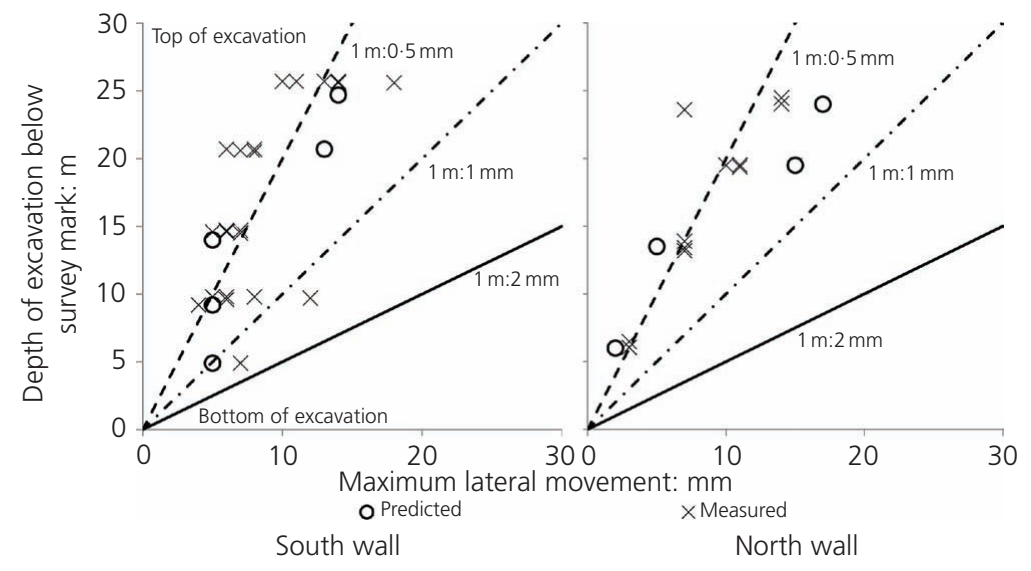

Figure 6. Lateral movement of the excavated face

analyses, in terms of the ground pressure acting on the wall, wall deflection and wall stresses.

Due to the station structure elastic, creep and shrinkage deformation, the ground pressure acting on the wall at the end of the excavation could be different from the long-term pressure post-degradation of the temporary support. Because of this, the ground pressure acting behind the temporary support piles was adopted to develop the station structures. Once the station structures were developed, the structural details were then incorporated into the geotechnical analysis and the temporary support was removed to model the load transfer onto the station structure. The ground relaxation due to long-term deformation of the station structure was considered. The refined ground pressures were adopted in the structural design, and further iterations were carried out until there was an agreement between the geotechnical and structural analyses.

Next, to analyse the effects of earthquake on the ground and station box wall, a pseudo-static approach was adopted. The horizontal ground acceleration for the Sydney region is $0.08 \mathrm{~g}$. Earthquake effects on underground structures can be broadly grouped into two categories: (a) ground failure such as kinematic instability of rock wedges and $(b)$ ground shaking (e.g. Hashash et al., 2001). The kinematic instability of rock wedge is addressed through kinematic analysis in Swedge by using a horizontal ground acceleration. The lateral wedge loads generated from global and localised failure mechanisms are assessed, and the station wall is designed to provide adequate ground support during seismic activity.

On the other hand, ground shaking produced by seismic waves would then cause deformations and strains on the station structure from the surrounding ground. This design requirement is captured through the FE approach. Hashash et al. (2001) reviewed the historical data on the performance of underground structures during a seismic event and observed that underground structures generally suffer from appreciably less damage than surface structures. Furthermore, they also observed that underground facilities constructed in competent rock suffer from less damage compared to those constructed in soils. The Sydney Metro Northwest underground stations are predominantly founded in medium-strength or better competent rocks with a relatively low level of seismic acceleration. These favourable conditions would reduce the risks for the underground stations. To analyse the deformation and strains caused by seismic waves to the Sydney Metro Northwest underground stations, a pseudo-static FE approach using RS2 was undertaken. This approach accounts for the interaction between the structural supports, the surrounding ground and the effect of earth mass removed during excavation, similar to that described in a manual by the Federal Highway Administration (FHWA, 2009). This was achieved by first applying the ground acceleration in RS2 to the entire soil-structure system in the horizontal direction in a pseudo-static manner, which would then result in an additional body force applied to each element in the mesh. The additional seismic force is automatically vectorially added by RS2 during calculation to the body force to obtain the total body force acting on the element. Next, the analysis is repeated by reversing the horizontal ground acceleration direction. The following direction conventions are assumed by RS2.

- A positive horizontal coefficient represents a force applied to the right.

- A negative horizontal coefficient represents a force applied to the left.

The assessed additional wall deformation (Figure 7) is then considered in the structural design.

\section{Results and discussion}

Figures 8(a) and 9(a) show the final design pressure envelope after deactivation of the temporary support. The pressure is lower compared to the equivalent pressure back-calculated from the 


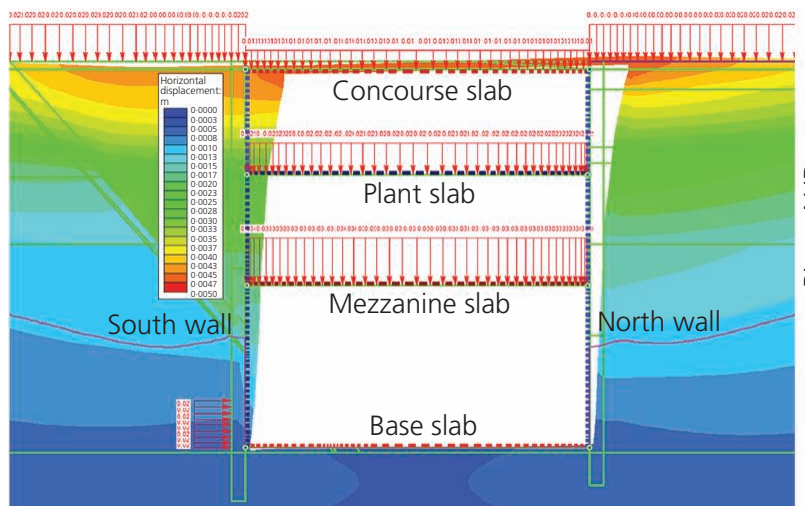

(a)

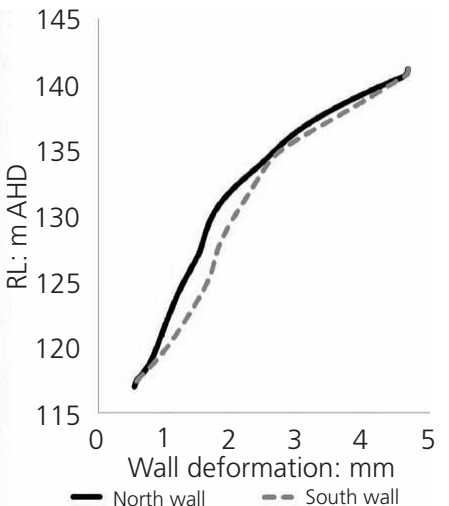

(b)

Figure 7. Additional seismic shear displacement under positive horizontal ground acceleration direction: (a) ground horizontal displacement contour; (b) wall deformation

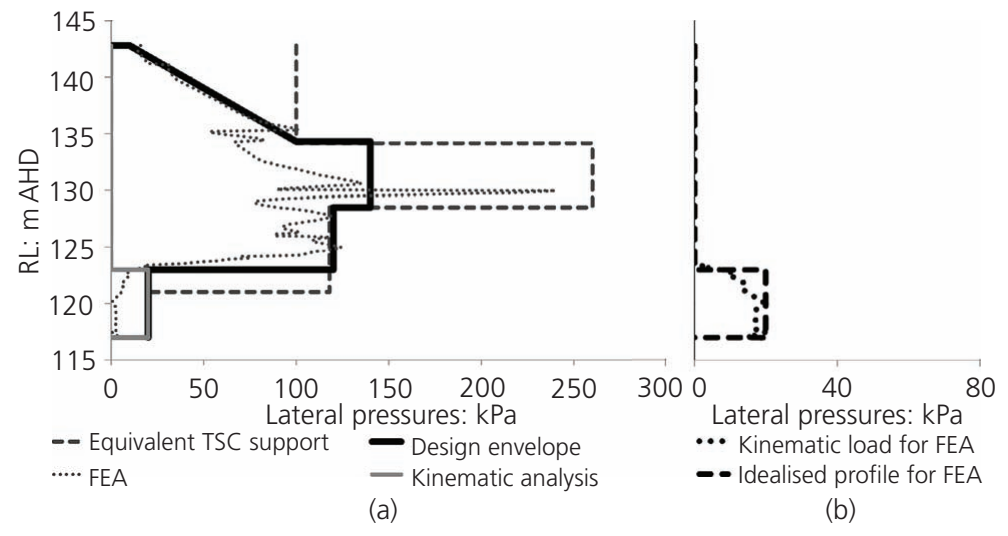

Figure 8. (a) Predicted ground pressure for the south wall; (b) the kinematic load applied to the FEA

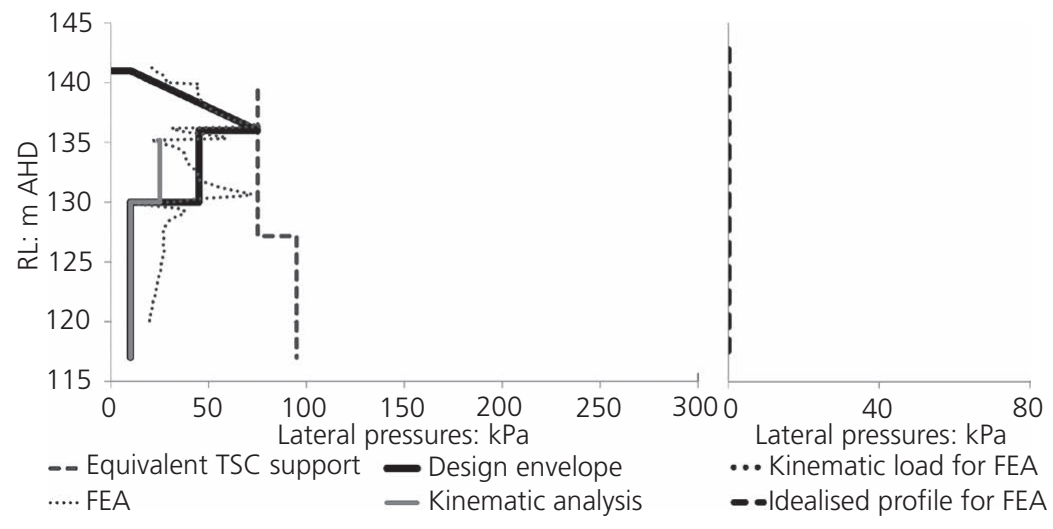

(a)

(b)

Figure 9. (a) Predicted ground pressure for the north wall; (b) no additional kinematic load is applied to the FEA 


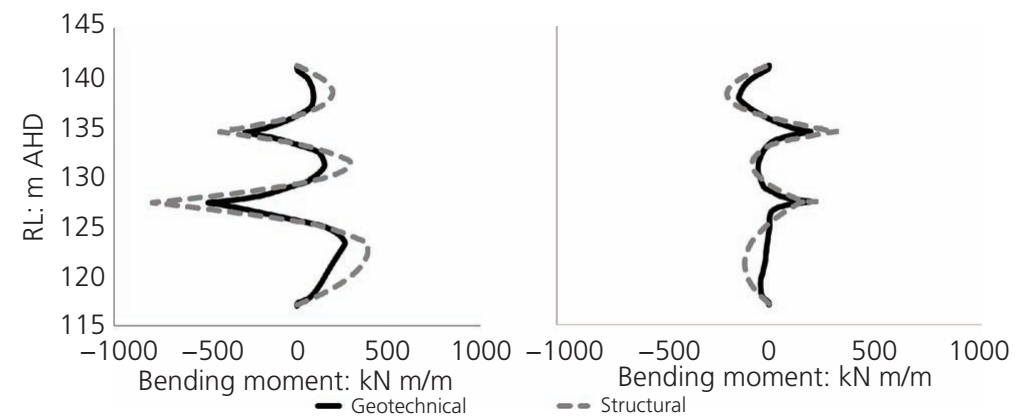

(a)

(b)

Figure 10. Predicted bending moment from the (a) south wall and (b) north wall

ground anchors/bolts due to the additional stress relaxation that occurs post-construction.

Figure 8(b) shows the wedge loading applied to the south wall in the FEA, which was determined from the difference between the kinematic and the residual pressure. No additional wedge loading was applied to the north wall (Figure 9(b)) as the residual pressure is higher than the kinematic pressure.

Figure 10 shows the bending moment of the station wall calculated from the structural and geotechnical analyses. The results show that through an integrated design approach, an agreement in the bending moment response of the station wall has been achieved between the geotechnical and structural analyses.

\section{Conclusion}

This paper demonstrates the importance of taking a holistic design approach to capture the effects of intricate ground stress relaxation history and ground-structure interaction. The approach took advantage of the geology mapping records and monitoring data to fine-tune the ground properties, wedge loading and locked-in stresses. The FE model was calibrated by comparing the predicted ground movements with the field measurements. Finetuning of the ground properties, wedge loading and field stresses was undertaken until the predicted ground movements were consistent with the measurements. The calibrated FE model was then used to predict the ground pressure for the station structures' design, which was optimised by considering the stress relaxation during excavation and post-degradation of the temporary support. The final design pressure envelope after degradation of the temporary support is assessed to be lower than the equivalent load back-calculated from the ground anchors. Through an integrated soil-structure interaction approach and calibration with the structural model, an agreement in the bending moment response of the station wall has been achieved between the geotechnical and structural analyses. By using the soil-structure interaction approach, the station wall thickness has been reduced from 800 to $500 \mathrm{~mm}$, achieving an economical solution.

\section{Acknowledgements}

The authors wish to thank the Cimic Group and one of its operating companies, CPB Contractors, for the use of the data and Dr Richard Kelly (Smec) for peer review.

\section{REFERENCES}

FHWA (Federal Highway Administration) (2009) Technical Manual for Design and Construction of Road Tunnels - Civil Elements. FHWA, US Department of Transportation, Washington, DC, USA, FHWANHI-09-010.

Hashash YMA, Hook JJ, Schmidt B and Yao JI (2001) Seismic design and analysis of underground structures. Tunnelling and Underground Space Technology 16(4): 247-293, https://doi.org/10.1016/S0886-7798 (01)00051-7.

Pells PJN, Mostyn G and Walker BF (1998) Foundations on sandstone and shale in the Sydney region. Australian Geomechanics - Journal and News of the Australian Geomechanics Society 33(3): 17-29.

\section{How can you contribute?}

To discuss this paper, please submit up to 500 words to the editor at journals@ice.org.uk. Your contribution will be forwarded to the author(s) for a reply and, if considered appropriate by the editorial board, it will be published as a discussion in a future issue of the journal. 